\title{
MOBILIDADE ESPACIAL, TEMPORAL E CONTEXTUAL: UM ESTUDO DE INSPIRAÇÃO ETNOGRÁFICA SOBRE O TRABALHO MÓVEL EM SHOPPING CENTER
}

\author{
SPATIAL, TEMPORAL AND CONTEXTUAL MOBILITY: \\ AN ETHNOGRAPHY APPROACH ABOUT \\ MOBILE WORK IN SHOPPING CENTER
}

\author{
Data de submissão: 19-11-2012 \\ Aceite: $17-08-2013$ \\ Kathiane Benedetti Corso ${ }^{1}$ \\ Neusa Rolita Cavedon ${ }^{2}$ \\ Henrique Freitas ${ }^{3}$
}

\section{RESUMO}

Este artigo busca entender o comportamento dos trabalhadores móveis, usuários de Tecnologias da Informação Móveis e Sem Fio (TIMS), em um shopping localizado em Porto Alegre, Rio Grande do Sul. De caráter etnográfico, por meio de entrevistas e observação, este estudo permitiu identificar que o shopping, como local de trabalho, significa para os entrevistados a otimização de um "tempo morto". Para lidar com fatores de dispersão intrínsecos ao shopping (mobilidade espacial), os trabalhadores móveis desenvolvem estratégias para driblar essas distrações. A mobilidade de tempo é vista como obstáculo em face da inexistência de separação dos tempos de trabalho e lazer, mas também como vantagem pela flexibilidade que ferramentas de comunicação oferecem. Verificou-se, ainda, que, quanto à mobilidade contextual, o e-mail cria uma relação indiscreta, adentrando na vida do indivíduo, de forma praticamente invasiva.

Palavras chave: trabalho móvel, mobilidade espacial, temporal, contextual, shopping.

\footnotetext{
${ }^{1}$ Possui graduação em Administração pela Universidade Federal de Santa Maria - UFSM, mestrado em Administração pela Universidade Federal de Santa Maria - UFSM e doutorado em Administração pela Universidade Federal do Rio Grande do Sul - UFRGS. Atualmente é professora adjunta da Universidade Federal do Pampa (UNIPAMPA) - Campus Santana do Livramento/RS. Santana do Livramento. Rio Grande do Sul. Brasil. E-mail: kathi.corso@gmail.com ou kathianecorso@unipampa.edu.br

2 Possui graduação em Ciências Econômicas, Administração Pública e Administração de Empresas pela Universidade Federal do Rio Grande do Sul - UFRGS, mestrado em Administração e Antropologia Social pela Universidade do Rio Grande do Sul UFRGS e doutorado em Administração pela Universidade Federal do Rio Grande do Sul - UFRGS. Atualmente é professora associada da Universidade Federal do Rio Grande do Sul - UFRGS. Porto Alegre. Rio Grande do Sul. Brasil. E-mail: nrcavedon@ea.ufrgs.br

${ }^{3}$ Possui doutorado em gestão pela Université Pierre Mendès France - UPMF, Grenoble, França. Atualmente é professor titular do Programa de Pós Graduação em Administração (UNINOVE). São Paulo. São Paulo. Brasil. E-mail: hf@uninove.br
} 


\section{ABSTRACT}

This paper aims to understand the behavior of mobile workers, users of Mobile and Wireless Technologies (MWT), in a shopping while workspace. Through an ethnographic look, with interviews and observation, picked up the Solar Shopping as a field of study. Shopping as a workplace means for respondents optimization "dead time". To deal with factors intrinsic to Shopping dispersion (spatial mobility), mobile workers develop strategies to dribble these distractions. The temporal mobility is seen as an obstacle in the face of lack of separation of work and leisure time, but also the advantage of the flexibility that communication tools offer. Concerning contextual mobility, email creates an obtrusive relationship entering in one's life, so almost invasive.

Keywords: mobile work, spatial, temporal, contextual mobility, shopping.

\section{INTRODUÇÃO}

O cenário do trabalho organizacional é apoiado, em grande parte, pelo uso de novas tecnologias de informação e comunicação, as quais propiciaram novos caminhos para o acesso à informação e vem se expandindo rapidamente desde o surgimento da internet. Com a disseminação das Tecnologias da Informação Móveis e Sem Fio (TIMS), é comum vermos pessoas circulando com seus dispositivos portáteis no dia a dia, em aeroportos, ônibus e shoppings, no do almoço, no jantar e em reuniões.

As tecnologias móveis caracterizam-se pela sua portabilidade, de forma que o usuário pode carregá-la para qualquer lugar, como ocorre com telefones celulares, notebooks, agendas eletrônicas, smartphones (telefones inteligentes) e PDAs (assistentes pessoais digitais). As tecnologias sem fio são aquelas que permitem o uso de dispositivos conectados a uma rede ou a um aparelho de comunicação sem fio, como as redes de telefonia celular, o infravermelho, o RFID (identificação por rádio frequência), a wireless LAN (rede local sem fio) e a wi-max (SACCOL; REINHARD, 2007).

O uso das TIMS faz parte do cotidiano de muitas empresas, propiciando a mobilidade do indivíduo. Essas tecnologias auxiliam nas atividades empresariais pelo rápido acesso aos colaboradores, na tomada de decisões, na busca de informações, em ações implementadas via telefones e notebooks com acesso à internet, possibilitando acesso a uma gama imensa de dados e informações em qualquer lugar e a qualquer hora. Diante disso, Perry et al. (2001, p. 323) afirmam ser necessária a incorporação pelo indivíduo dessa nova forma de atuação profissional:

Os movimentos rápidos e acelerados em direção ao uso de tecnologias móveis têm cada vez mais fornecido pessoas e organizações com a habilidade para trabalhar longe do escritório e se mover. Os novos meios de trabalho proporcionados por estas tecnologias são frequentemente caracterizados em termos de acesso a informação e as pessoas, a qualquer hora e qualquer lugar.

Apesar de certas restrições quanto ao custo, à disponibilidade, aos padrões universais e à segurança, as TIMS têm se propagado mundialmente e, da mesma forma, no mercado brasileiro (SACCOL; REINHARD, 2007). Essas tecnologias se tornam cada vez mais populares nas mais diversas áreas de atividade, devido à sua simplicidade, funcionalidade, portabilidade e facilidade de utilização (MYERS et al., 2004). Mark Donovan, vice-presidente de mobile da comScore, em entrevista à IDG NOW (2012), afirmou que o ano de 2011 se mostrou um período de inovação para a indústria móvel, quando os smartphones se tornaram populares, os tablets emergiram como uma quarta tela e os consumidores integraram cada vez mais comportamentos móveis em seu estilo de vida.

No que tange ao uso de TIMS no contexto organizacional, dados de uma pesquisa realizada 
pela Wakefield Research com executivos em setembro de 2012 revelam que 67\% das empresas brasileiras afirmaram que seus funcionários, em sua maioria, usam smartphones para tarefas básicas do trabalho, como leitura de e-mails, documentos da internet e calendário (ADMINISTRADORES.COM, 2012). As previsões do Gartner Group são de que, até 2016, mais de 1,6 bilhão de dispositivos móveis inteligentes serão comprados globalmente, o que significa que dois terços da força de trabalho móvel possuirão um smartphone e que $40 \%$ da força de trabalho será móvel (COMPUTERWORLD, 2012).

É possível, portanto, antever uma tendência, cada vez maior, do uso de TIMS. A essa constatação alia-se o número crescente de empresas que vem oferecendo a possibilidade de trabalho móvel aos seus colaboradores. Várias forças motrizes demonstram que esse tipo de trabalho está ganhando impulso no âmbito profissional, tais como a redução de custos, o aumento dos lucros econômicos e a maior necessidade e preferência dos trabalhadores por esse tipo de trabalho (ANDRIESSEN; VARTIAINEN, 2006).

Pode-se afirmar que ainda são poucos os estudos da área de Tecnologia de Informação que se apoiam em pesquisas de inspiração etnográfica como método e buscam na Antropologia explicações para os fenômenos. Especificamente quanto ao uso de TIMS e ao Trabalho Móvel, não foram encontrados estudos antropológicos significativos. A esse respeito, Cavedon (2003) destaca a importância de um estudo interdisciplinar e ressalta que o conhecimento administrativo se constrói por meio do diálogo com várias disciplinas. Assim, entender um fenômeno ligado ao uso de tecnologia, com inspiração em um método clássico da Antropologia, é relevante para a área de Sistemas de Informações, que vem procurando apreender mais sobre a relação e interação "homem versus máquina".

Diante disso, o objetivo deste estudo consiste em compreender o comportamento dos trabalhadores móveis, usuários de TIMS, em um shopping center. Já os objetivos específicos são: (a) identificar o significado do trabalho móvel em um shopping center; e (b) compreender como os trabalhadores móveis lidam com as sobreposições de espaço, tempo e contexto (ao utilizarem as TIMS). Embora existam vários artigos nacionais sobre o tema shopping center's (SILVEIRA; SINEM, 2009; VANCE; ANGELO; FOUTO, 2009; dentre outros), não foi possível identificar pesquisas referentes ao trabalho realizado por meio de tecnologias neste tipo de estabelecimento.

Dessa forma, optou-se por realizar este estudo de inspiração etnográfica em um espaço do Solar Shopping (esse nome é fictício) em que é possível encontrar pessoas trabalhando com seus dispositivos tecnológicos e utilizando-se da internet. As técnicas da observação sistemática e a realização de entrevistas semiestruturadas permitiram a obtenção dos dados visando à concretização do estudo.

A fim de proceder aos objetivos propostos, este artigo está estruturado em quatro seções, além desta introdução. Na seção 2 , apresenta-se o referencial teórico que embasa a análise dos achados de campo, seguido do método de estudo, na seção seguinte, que evidencia o caminho percorrido para alcançar o objetivo da pesquisa. Na quarta seção, discorre-se acerca dos resultados obtidos e, por fim, na última seção, são apresentadas as considerações finais.

\section{O USO DE TECNOLOGIAS DA INFORMAÇÃO MÓVEIS E SEM FIO: TRABALHO MÓVEL E MOBILIDADE}

As novas tecnologias que surgiram nos últimos anos têm em comum a diminuição de tamanho e peso. Essa miniaturização dos equipamentos possibilitou o lançamento de tecnologias móveis, como notebooks, PDAs (assistentes pessoais digitais), smartphones (conhecidos como telefones inteligentes), telefones celulares e agendas eletrônicas. As Tecnologias de Informação Móveis, advindas do termo mobile, tem como característica a portabilidade, isto é, a capacidade de ser levado para qualquer lugar (SACCOL; REINHARD, 2007). Já as Tecnologias de Informação 
Sem Fio, do inglês wireless, são aquelas que envolvem o uso de dispositivos conectados a uma rede ou a outro aparelho via links de comunicação sem fio, cujos exemplos são: as redes de telefonia celular, a transmissão de dados via satélite, o infravermelho, o bluetooth, a RFID (identificação por rádio frequência), a wireless LAN (rede local sem fio) e a wi-max.

A adoção das tecnologias móveis vêm acompanhada de impactos sociais em diversas partes do globo, como ressaltam Castells et al. (2004), pois as pessoas se apropriam de seus atributos e funcionalidades de forma que essas tecnologias passam a fazer, cada vez mais, parte de seu cotidiano, gerando para certos usuários dependência. "As mudanças tecnológicas, particularmente os desenvolvimentos em Tecnologias de Informação e Comunicação (TICs) móveis e sem fio, criam possibilidades para trabalhar em qualquer lugar e momento" (ANDRIESSEN; VARTIAINEN, 2006, p. 4), de modo que o indivíduo pode acessar, manipular e trocar informações.

O Trabalho Móvel adquire, assim, dois sentidos: estrito, como no caso de documentos e tarefas que se movem fisicamente ou digitalmente, e amplo, quando se refere ao trabalho dos trabalhadores móveis (ANDRIESSEN; VARTIAINEN, 2006). O fato de denominar de móvel esse tipo de trabalho se justifica por se tratar de uma atividade que utiliza TIMS, permitindo não só estar longe e distante do local tradicional de trabalho, mas em movimento e em qualquer lugar. Dessa forma, o Trabalho Virtual Móvel implica o interesse pelos:

cenários que foram distribuídos fisicamente e pelas pessoas móveis que interagem por meio das infraestruturas digitais e ferramentas móveis para desempenhar suas tarefas em um contexto organizacional que tem uma estrutura e cultura orientada para a mobilidade (ANDRIESSEN; VARTIAINEN, 2006, p. 7).

Para Kornak (2004), mobilidade é a aplicação de dispositivos móveis e tecnologias sem fio que permitem a comunicação, o acesso à informação e a realização de transações de negócios a partir de qualquer dispositivo, de qualquer lugar e a qualquer momento. Na sua definição, o autor evidencia que "móvel" e "sem fio" são conceitos que podem ser usados como entidades não necessariamente separadas, aparecendo juntas na definição de mobilidade, por exemplo.

Entretanto, conforme Kakihara e Sorensen (2002), o conceito de mobilidade não deve ser exclusivamente relacionado ao aspecto espacial, isto é, à questão geográfica de deslocamento corporal dos indivíduos, como comumente ocorre na literatura. Os autores expandem a perspectiva geográfica, defendendo que as tecnologias móveis oportunizam novas dimensões à interação entre as pessoas, possibilitando a mobilidade espacial, temporal e contextual. Assim, os autores defendem que:

[...] "ser móvel" não é só uma questão das pessoas que viajam, mas, muito mais importante, relacionada à interação que elas desempenham - a maneira pela qual elas interagem umas com as outras em suas vidas sociais (KAKIHARA; SORENSEN, 2002, p. 1).

Dessa forma, o uso das Tecnologias da Informação Móveis e Sem Fio (TIMS) propicia que os indivíduos exerçam diferentes papéis sociais de maneira irrestrita, independentemente de tempo e espaço. Como ressaltam Loureiro et al. (2004), esse novo paradigma da mobilidade vêm mudando a forma como as pessoas trabalham, se comunicam, se divertem, estudam e realizam outras atividades. Na acepção de Kakihara e Sorensen (2002), a Mobilidade Espacial denota o aspecto mais imediato da mobilidade na vida em sociedade e manifesta-se, por exemplo, desde o aumento das viagens de negócios e turismo no século 20. Esse é o motivo pelo qual alguns autores (KLEINROCK, 2001; CHEN; NATH, 2005) cunharam de "nômades" os indivíduos que se movem geograficamente sendo suportados por diferentes tecnologias, como os celulares, os smartphones e os notebooks, por exemplo. 
Kakihara e Sorensen (2002) asseveram que analisar a mobilidade apenas sob a perspectiva da circulação de seres humanos impossibilita a captura da complexa realidade que emerge da mobilidade na vida social, ficando a análise restrita a uma concepção funcionalista. Para os autores, a "mobilização da espacialidade na interação humana resulta do fluxo rápido e complexo de todas as entidades que vivem em nosso mundo, incluindo não somente humanos, mas também objetos, símbolos e imagens" (2002, p. 2).

Outro aspecto da mobilidade social de interação entre as pessoas que utilizam as tecnologias de informação móveis está relacionado à temporalidade. A mobilidade temporal, segundo Kakihara e Sorensen (2002), advém em grande parte dos esforços empreendidos para criar novas tecnologias que acelerassem o ritmo de trabalho e para economizar tempo, embora essas não sejam as únicas transformações temporais induzidas pelas novas tecnologias. As mudanças de temporalidade causadas nos locais de trabalho podem ser discutidas em termos do que Orlikowsky e Yates (2002) definem como tempo objetivo e subjetivo, isto é, o tempo "do relógio" (linear-quantitativo, que existe independentemente da ação humana) e o tempo socialmente construído (relativo aos significados intersubjetivos compartilhados).

Nesse sentido, Barley (1988) caracteriza a temporalidade usando a dicotomia monocronicidade e policronicidade. $O$ primeiro termo refere-se às situações em que as pessoas procuram estruturar suas atividades alocando faixas de horários específicas para a ocorrência de cada evento. Já o segundo refere-se às situações em que as pessoas concedem menos valor a essa rigidez e aceitam a divergência de atributos estruturais e interpretativos de ordem temporal.

Considerando a recente difusão das TIC's na vida social e as decorrentes mudanças na noção de tempo, na sequência e duração de eventos e nos ritmos de vida e trabalho, a tendência é o rápido aumento da policronicidade. Segundo Kakihara e Sorensen (2002), é possível assegurar que a "instantaneidade" do tempo na sociedade contemporânea, em geral e no ciberespaço, aumenta ainda mais a policronicidade das atividades humanas. Os autores entendem que a dimensão temporal da interação humana não pode mais ser explicada sob a perspectiva do tempo linear, o "tempo do relógio", pois ela é agora mobilizada de vários modos, com base na perspectiva de cada ator. Assim, tem-se um ambiente social complexo em que a monocronicidade e a policronicidade de interação se entrelaçam.

Outra importante dimensão da mobilidade facilitada pelo uso das TIMS é a contextualidade, ou seja, as múltiplas interações e mudanças nas relações sociais. A mobilidade contextual ou social, conforme Kakihara e Sorensen (2002), remete aos aspectos interacionais, tais como "de que maneira", "em que circunstância particular" e "para que ator (es)" a ação é desempenhada. Nesse sentido, Ljungberg e Sorensen (2000) caracterizam a mobilidade de interação em duas dimensões: discretas versus indiscretas e efêmera versus persistente.

Nessa lógica, a interação pode ser mais ou menos indiscreta, dependendo do rigor que ela impõe às obrigações para advertir ou reagir. Ao mesmo tempo, a interação pode variar entre a interação efêmera, que só existe no fluxo de atividades manifestadas em determinado momento, e a interação persistente, que necessita de uma inspeção e discussão mais aprofundada. Um e-mail recebido que exige resposta urgente do receptor, por exemplo, pode ser visto como uma interação persistente indiscreta. Desse modo, devido às várias aplicações de TIC's, as pessoas podem facilmente interagir umas com as outras relativamente livres das relações de contexto (KAKIHARA; SORENSEN, 2002). 


\section{CONSTRUINDO O CAMPO "MÓVEL": O MÉTODO DE ESTUDO}

O campo de estudo escolhido para compreender o fenômeno do trabalho móvel foi o Solar Shopping, localizado na cidade de Porto Alegre, Rio Grande do Sul. Como observar algo que não possui um lugar fixo para a sua consecução, já que trabalhadores móveis que fazem uso de Tecnologias da Informação Móveis e Sem Fio (TIMS) podem trabalhar em qualquer lugar? Todavia, como, com frequência, é possível ver pessoas, no Solar Shopping, exercendo suas atividades laborais, este foi o local escolhido para realização desta pesquisa.

Para estudar o fenômeno em questão, procedeu-se a um estudo de inspiração etnográfica, assim qualificado em razão do número bastante reduzido de idas a campo. Conforme Cavedon (2003, p. 143), a etnografia é "[...] o levantamento de todos os dados possíveis sobre uma determinada comunidade com a finalidade de melhor conhecer o estilo de vida ou a cultura específica da mesma". Logo, a escolha desse método para investigar o fenômeno do trabalho móvel ocorreu pela possibilidade de observação dos comportamentos, das atitudes, dos sinais, dos símbolos, das reações e dos sentimentos dos trabalhadores móveis, usuários de TIMS, em momentos de atividades profissionais em um local que pode se configurar muitas vezes como de lazer.

Dentre as técnicas utilizadas para a realização desta pesquisa, figuram a observação sistemática e a realização de entrevistas semiestruturadas. Foram feitas seis inserções em campo, entre os dias 18 de maio e 23 de junho de 2010, ocorrendo aproximadamente uma visita por semana em dias alternados. O horário que pareceu ser o mais apropriado para encontrar os trabalhadores móveis foi o das $16 \mathrm{~h}$ às $18 \mathrm{~h} 30 \mathrm{~min}$. Além das observações feitas a cada inserção, totalizando seis diários de campo, foram realizadas nove entrevistas semiestruturadas com diferentes indivíduos. Registros visuais também foram realizados para melhor capturar e interpretar certos elementos obtidos nas entrevistas e observações.

Durante as inserções em campo, as falas dos entrevistados foram gravadas e posteriormente transcritas. Todas as observações foram anotadas ainda em campo em um caderno e posteriormente detalhadas nos diários de campo. Como lembra Malinowski (1978, p. 18),

[...] um trabalho etnográfico só terá valor científico irrefutável se nos permitir distinguir claramente de um lado, os resultados da observação direta e das declarações e interpretações nativas e, de outro, as inferências do autor, baseadas em seu próprio bomsenso e intuição psicológica.

Assim, a interpretação e a escrita dos dados precisam ser consoantes com aquilo que é preconizado pelo fazer etnográfico, em que as vozes dos informantes, da pesquisadora e dos teóricos estão em diálogo.

\section{NA MOBILIDADE DO CAMPO}

A entrada no campo aconteceu de forma tranquila, visto ser um local público, sem dono e onde, em princípio, a pesquisadora era apenas mais uma pessoa nesse não lugar, que entrou no shopping como se fosse a primeira vez, propondo-se, como em todas as demais inserções, a obter o "estranhamento" (VELHO, 1981) e dessa forma, captar todas as informações e percepções do modo mais abrangente possível. 


\subsection{0 "cantinho de trabalho" da praça de alimentação do Solar Shopping: que lugar é esse?}

O Solar Shopping, situado próximo ao centro de Porto Alegre, é um ponto de referência para as mais de 1,4 milhão de pessoas residentes na capital gaúcha e milhares de turistas que a visitam anualmente. $O$ empreendimento procura dar espaço para todo tipo de público, atraindo diversos segmentos de consumidores. O Shopping apresenta um mix composto de 186 lojas distribuídas em dois pisos, oferecendo variedade e qualidade aos exigentes consumidores da região, além de possuir todas as características de um complexo de compras e lazer de sucesso (SOLAR SHOPPING, 2010). A escolha deste Shopping para a realização do estudo ocorreu em função de as pessoas comentarem que, na entrada da praça de alimentação, havia um pequeno local onde regularmente indivíduos podem ser encontrados trabalhando com seus notebooks e celulares.

Esse espaço fica localizado sob o ângulo de três pilares em formato de um " $L$ " no segundo piso do Shopping. É um "cantinho" aberto, composto de quatro mesas redondas, cada uma com quatro cadeiras, e possui uma espécie de "muro" que o separa da praça de alimentação. No centro daqueles aparentes $25 \mathrm{~m}^{2}$, há um mastro de madeira com um guarda-sol verde-escuro. Do outro lado do muro, há uma bancada com banquetas, onde é possível também alocar algum ferramental de trabalho. Na parte interna, sob o " $L$ " das paredes, encontram-se vasos brancos com folhagens verdes, a fim de conceder um "ar de natureza" ao pequeno espaço. Alguns detalhes parecem limitar o trabalho de quem ali permanece: há somente uma tomada disponível para carregar a bateria de notebooks ou celulares. Além disso, naquela área, só há uma lâmpada.

Apesar de o espaço não conter algo que o identifique como sendo uma área com wireless, permitindo, assim, que trabalhadores móveis exerçam ali suas atividades, observa-se um apelo de marketing sobre a venda de aparelhos celulares muito próximo àquela área. Um banner gigantesco, de aproximadamente $6 \mathrm{~m} \times 9 \mathrm{~m}$, estava suspenso no vão entre as escadas, com uma propaganda de uma operadora de telefonia divulgando ofertas de smartphones. O banner fica visível aos olhos dos que estão sentados nas mesinhas trabalhando. Ainda próximo ao "cantinho", no corrimão do corredor, há um pequeno painel digital, fixo, com uma propaganda similar.

Assim, embora esse local não seja identificado como um espaço para usuários de TIMS, ele é legitimado como tal. Isso pode ser confirmado pelo fato de que, se alguém perguntar no Balcão de Informações do Shopping onde há acesso à internet wireless, a resposta é de que o Shopping não disponibiliza internet. Na verdade, apesar de o Shopping não ter um link de acesso à internet disponível aos seus frequentadores, as pessoas que vão ao "cantinho", quando precisam de navegação, acessam a internet por meio de seus próprios aparelhos " $3 G$ " ou buscam alguma rede de internet das lojas da praça de alimentação. Ressalta-se, contudo, que os usuários demonstram indignação com o fato de o Shopping não oferecer internet, algo tido como essencial, como se observa na fala de um informante: "Eu acho um absurdo; internet é quase que uma luz" (Informante 4).

\subsection{Trabalhadores móveis: quem são, o que fazem e por que fazem}

Buscando conhecer os trabalhadores móveis, apresenta-se, a seguir, o Quadro 1, que contém um breve perfil quanto ao gênero, à profissão, à empresa e sua localização e à idade dos usuários do "cantinho". Como é possível observar, a maioria dos que frequentam o local para trabalhar com suas tecnologias são homens e adultos na faixa etária dos 24 aos 53 anos. Foi possível identificar dois tipos de trabalhadores móveis: os profissionais liberais, autônomos, e aqueles vinculados a alguma empresa, destacando-se os de telefonia e da área de vendas.

A idade revela uma faixa etária de profissionais em período laboral ativo. A exceção, 
dentre os informantes, foi uma senhora de 76 anos, advogada, professora universitária e escritora (Informante 2), que se diz "internauta juramentada" e que demonstrava enorme prazer em estar ali trabalhando. Com exceção do Informante 2 e do Informante 6, um senhor grisalho, com voz serena e olhar tranquilo, grande parte deles aparentava pressa e concentração no olhar, revelando o compromisso com o trabalho, apesar de estar fora do local físico da organização. Sempre quando abordados, pediam mais alguns minutos para terminar a tarefa que estavam realizando. Essa característica ficou evidente principalmente nos coordenadores e promotores de vendas.

\begin{tabular}{|c|c|c|c|}
\hline $\begin{array}{l}\text { TRABALHADOR } \\
\text { MÓVEL }\end{array}$ & PROFISSÃO & EMPRESA/LOCALIZAÇÃO & IDADE \\
\hline 1-mulher & Coordenadora de Vendas & Confecções de Lingerie - Guaporé/RS & 30 \\
\hline 2-homem & Coordenador de Vendas & Telefonia Empresarial (Claro) - POA/RS & 37 \\
\hline 3-homem & Técnico em Copiadoras & Empresa de Novo Hamburgo/RS & 28 \\
\hline 4-mulher & $\begin{array}{l}\text { Advogada, Profa. Universi- } \\
\text { tária aposentada, Escritora }\end{array}$ & Profissional Liberal - POA & 76 \\
\hline 5-homem & Advogado & Escritório de Advocacia - Florianópolis/SC & 32 \\
\hline 6-homem & Engenheiro Elétrico & Empresa - Região Metropolitana & 53 \\
\hline 7-homem & $\begin{array}{c}\text { Investidor da Bolsa de Va- } \\
\text { lores }\end{array}$ & Profissional Liberal - POA & 37 \\
\hline 8-homem & Fotógrafo & Profissional Liberal - POA & 28 \\
\hline 9-homem & Promotor de Vendas & Sony Ericsson - SC & 24 \\
\hline
\end{tabular}

Quadro 1: Perfil dos Trabalhadores Móveis do Solar Shopping

Um questionamento presente desde o início deste estudo era o motivo pelo qual as pessoas saíam de suas casas ou de seus ambientes de trabalho para trabalharem ali, em um espaço público, onde circulam centenas de pessoas diariamente, sendo o barulho e a agitação constantes. No geral, os informantes não têm assiduidade em frequentar o Shopping, não sendo possível, por exemplo, reencontrar o mesmo indivíduo nas diferentes visitas realizadas.

Conversando com os trabalhadores móveis, observa-se que são dois os principais motivos para trabalhar no Shopping: estão em viagem e procuram um local para se estabelecer naquele dia ou querem aproveitar uma "sobra" de tempo do seu dia, evitando deslocamentos. Aqueles que estão em viagem relataram estar visitando clientes próximos dali, de modo que o Shopping surge como alternativa de permanência até o momento das reuniões, como se constata na fala de um deles:

Eu passo viajando... é tudo via conexão remota, trabalho todo dia assim. Trabalho com representantes, tenho reuniões com clientes. Como estou próxima da região que eu tenho que ir para fazer uma reunião, eu vim aqui, para dar um tempinho e abrir meus e-mails (Informante 1).

Outros trabalhadores móveis evidenciaram que o Shopping é um local para "paradas estratégicas", ou seja, para quando precisam realizar uma tarefa com certa urgência e estão nas proximidades do Shopping, caso em que um possível deslocamento para outro lugar seria inadequado devido ao tempo gasto no trânsito. Em diversos momentos, são feitas referências a isso:

Porque às vezes eu vou num cliente que é perto um do outro e tem um intervalo de uma, duas horas entre uma visita e outra e voltar para o escritório para depois ir no cliente de novo, fica contramão. Então às vezes eu paro pra trabalhar em algum lugar, no Shopping, ou algum lugar perto [...] Hoje eu tinha que mandar uns e-mails até às 18 horas, e responder umas coisas... não conseguiria chegar em casa, nem no escritório [...] eu tinha que resolver! (Informante 2). 
Eu me desloco muito. Vou até alguns clientes na Grande Porto Alegre. Então, às vezes fica fora de mão eu ir até em casa trabalhar. Moro longe... na Zona Sul. Então, às vezes eu chego em casa e surge algum assunto que eu tenho que voltar.... Então, eu faço essas paradas estratégicas (Informante 6).

Eu tinha algumas coisas pra resolver aqui perto. Aí, eu aproveitei pra vir ao Shopping porque coincidiu com o trabalho, com o horário que eu tinha que acessar a net. [...] A Bolsa de Valores fecha às cinco... e a maior quantidade de negócios ocorre na última hora, às 4, às 5... Então, eram 3:30, eu me liberei e até chegar em casa, não ia dar tempo, né. Então eu vim aqui pro Shopping... assim consigo acessar a internet e ainda trabalhar... fazer algum negócio (Informante 7).

Seja para evitar deslocamentos e realizar atividades, seja porque estão em viagem em busca de um locar para trabalhar, os trabalhadores móveis procuram otimizar o tempo decorrido entre tarefas e/ou reuniões. Nesse sentido, Perry et al. (2001), ao buscarem entender a natureza do trabalhador móvel, evidenciaram o modo como as tecnologias móveis foram usadas para maximizar a flexibilidade e o acesso à informação no que tange às atividades de trabalho, caracterizando o "tempo morto", o "tempo de viagem", o "tempo livre" e o "tempo desperdiçado" como os momentos em que o indivíduo está esperando voos, reuniões, consultas ou tráfego, podendo então trabalhar para não ficar ocioso. Desse modo, em períodos de "tempo morto", eles buscam gerenciar suas tarefas e utilizar esse tempo para algum tipo de atividade.

Quanto às tecnologias utilizadas para trabalhar de forma móvel, foi possível notar que todos portavam notebook de tamanho grande, em torno de 13 a 16 polegadas, sendo alguns aparentemente antigos. Chama a atenção, também, o fato de estarem se locomovendo com tal máquina de um lugar para o outro. Nenhum deles tinha netbook, uma espécie de notebook em tamanho menor, entre 8 e 11 polegadas, que é mais leve e pequeno que o tradicional notebook. Os dois coordenadores de vendas entrevistados são os trabalhadores móveis que estavam equipados mais adequadamente, com dispositivos móveis e sem fio. Ambos utilizavam notebook, celular e smartphone.

A maioria dos trabalhadores móveis utiliza softwares básicos do tipo Word, Excel, Power Point, agenda e softwares de controle de rotinas internas. Destaca-se o e-mail como principal ferramenta de comunicação, seja no notebook ou no smartphone, como constatado nas falas: "[...] por meio do celular com internet acesso meus e-mails a toda hora, e daí vou dando retorno..." (Informante 1); "A necessidade do e-mail pra mim envolve receber minhas ordens de serviço" (Informante 3); "Troca de e-mail, pesquisas de informações desde notícias até jurisprudências, né [...] comunicação com clientes... com o próprio escritório" (Informante 5).

Questionados se sentiam falta de alguma coisa, seja em termos de equipamento ou pessoa, quando estavam trabalhando ali, mencionaram a impressora como a principal carência quando se trabalha dessa forma. Nas palavras de um deles, coordenador de vendas que realiza constantemente visitas a clientes, a impressora faz falta "para imprimir os contratos" (Informante 2). Um informante, que também mencionou essa carência, afirmou: "Olha, eu acho que, hoje, com o que a gente tem de tecnologia disponível, no máximo uma impressora" (Informante 5).

\subsection{Enfrentando as sobreposições de espaço, tempo e contexto}

Um dos objetivos específicos deste estudo foi compreender como os trabalhadores móveis lidam com as sobreposições de espaço, tempo e contexto, dimensões da mobilidade propiciadas pelo uso das TIMS (KAKIHARA; SORENSEN, 2002). 


\subsubsection{O local: conectados em todo lugar}

Com relação à mobilidade espacial oportunizada pelo uso das TIMS, os trabalhadores móveis elencaram diversos outros locais além do Shopping que costumam frequentar para trabaIhar, como hotéis, ônibus e avião: "Não tem local bem-definido... até em hospital!" (Informante 2). Fica evidente que todo lugar é propício ao uso dessas tecnologias para o trabalho, como revelam dois informantes: "Eu me conecto em tudo que eu vou. Em Lisboa, em Madri, onde eu andar, eu estou conectada [...] eu uso também na praia" (Informante 4); "Às vezes a gente vai almoçar, ou fazer um lanche, alguma coisa, e estou ali ligado nos e-mails" (Informante 2).

Como a mobilidade espacial remete ao fluxo não só de pessoas, mas também de objetos e símbolos, a observação e as entrevistas com os usuários permitiram verificar a portabilidade de ferramentas, como o smartphone, como uma maneira de carregarem a agenda para qualquer lugar e assim terem acesso aos seus compromissos, como destaca um dos informantes:

Ah, uma coisa muito boa é a Agenda dele (smartphone), que aí conecta no notebook. Depois de... 15, 18 anos, dá pra dizer que é o primeiro ano que eu não uso agenda no papel. É... isso é uma mudança, né? Bem difícil tu largar. Foi mais de um mês pra me adaptar [...] porque aí eu conecto ele aqui, né? Aí eu digito tudo aqui (no notebook) e já tá ali (no smartphone). Então, se tu não tá com o note ligado tu consegue, em trânsito, acessar ali... a Agenda eu tenho toda aqui. O que me facilita bastante é pra isso (Informante 7).

Ainda com relação ao local, indagados sobre como se sentem trabalhando em um local que não o tradicional de uma empresa, aqueles que estavam em viagem relataram que não veem problema em se deslocar e ali trabalhar, como enfatizou a Informante 1: "Eu gosto, sempre gostei de viajar, então, pra mim é bem fácil trabalhar assim". Todavia, alguns obstáculos foram relatados em razão de estarem em atividade em um shopping center, como o barulho, o fluxo de pessoas ou até mesmo o aroma da comida:

É interessante porque é diferente de tá dentro de uma sala de escritório, né. Exige mais concentração porque é gente passando toda hora, tem gente na mesa do lado conversando, então pra não te chamar a atenção sobre o assunto que tá do lado... Às vezes um cheirinho de comida, né... (Informante 5).

Diante do ruído que permeia o local, algumas estratégias são articuladas pelos trabalhadores móveis, como a escolha por se dedicarem a tarefas de baixa complexidade, a exemplo do que é referenciado nas seguintes falas:

\footnotetext{
Tem certas atividades, quando é só responder algum e-mail, ou ler alguma coisa, atualizar coisas, é... se consegue. Agora, tem determinadas atividades que você tem que se concentrar um pouco mais. Aí é mais difícil. Aí eu deixo aquele assunto eu deixo pra tratar num outro momento, num ambiente mais calmo (Informante 6).

Mas quando eu estou fazendo alguma coisa, assim, mais complexa, montando uma proposta ou coisa, aí eu faço no escritório geralmente. Ou em casa, de noite. Aqui é mais operacional (Informante 2).
}

A falta de concentração também é contornada por um informante, através do uso de um aparelho protetor de ouvidos, conforme ele explica: "Eu até tenho um abafador aqui, aquele pequeninho da 3M, tira 80\% do som" (Informante 7).

A agitação do Shopping é destacada por uma entrevistada, que explica ter uma sensação bastante diferente de quando está trabalhando em outro local, como um hotel, por exemplo: 
Então, assim, quando eu estou trabalhando no hotel eu realmente tenho uma sensação mais leve. Eu sou mais suave, é tudo mais tranquilo. No Shopping eu fico agitada. Agitada mesmo (Informante 4).

\subsubsection{O tempo: a busca por limites}

Referente à mobilidade temporal, decorrente do uso das TIMS, foi possível identificar duas formas de lidar com o tempo: o tempo objetivo e o tempo subjetivo (ORLIKOWSKI; YATES, 2002). Na fala de um trabalhador móvel, é possível verificar a corrida contra o tempo "do relógio", quando afirma, em tempo gerúndio, que está fazendo três coisas ao mesmo tempo - a policronicidade de atividades, como destacado por Barley (1988): "Estou almoçando, estou lendo os e-mails e respondendo" (Informante 2). Já o tempo subjetivo foi identificado por um coordenador de vendas, que, ao tomar café, tinha as mãos suadas, aparentando não estar dando conta do que fazia, mas enfatizando: "Eu faço meu horário... Prefiro assim até" (Informante 2). Ele confirmava a monocronicidade de suas atividades, organizando seus horários de visitas aos clientes em faixas específicas de horários, conforme a sua disponibilidade.

Apesar de os trabalhadores móveis afirmarem serem regrados quanto aos horários que disponibilizam para o trabalho, a fala seguinte revela um descontrole do tempo:

Esse eu acho que é um ponto negativo dessa tecnologia, que a gente acaba não pondo limite no horário. Então, eu realmente não tenho horário... Às vezes a gente aproveita um horário que todo mundo está trabalhando e faz alguma outra coisa que, ou porque precisa ser feito... ou porque bateu um cansaço e tu resolve fazer alguma coisa, fora desse horário, mas daí depois tu acaba compensando e trabalha à noite, em feriados, fim de semana... Às vezes quando viaja, tá num hotel, aí quando vê tu tá até altas horas trabalhando... respondendo e-mails... (Informante 6).

Esse informante afirma não ter limite de horários estabelecidos, ou seja, trabalha com a policronicidade de atividades, - demonstrando, entretanto, descontentamento e agitação. Por outro lado, ressaltou um benefício temporal quando questionado sobre a falta de alguma coisa ao realizar trabalho móvel:

Eu acho que as ferramentas que se tem compensam as faltas, né... do contato... Porque a gente acaba se acostumando... assim como a gente responde aos problemas na hora que a gente acha melhor, a nossa hora, na hora que a gente tem a resposta... temos que aceitar que os outros também têm esse prazo pra pensar e responder. Quando tu tá cara a cara, por exemplo, você me pergunta, eu tenho que te dar a resposta agora. Mas com essas ferramentas tu te escondes às vezes... E tu ficas pensando numa melhor resposta, num melhor momento (Informante 6).

A fala desse informante remete ao uso do e-mail como ferramenta que possibilita uma assincronicidade, isto é, a possibilidade de resposta em tempos diferentes. Assim, é possível "se esconder" atrás do e-mail e responder no melhor momento, ganhando tempo para pensar.

\subsubsection{O contexto: lidando com mundos diferentes}

Buscando entender como os trabalhadores móveis lidam com a interação entre seus diferentes papéis sociais quando estão utilizando as TIMS, foram identificados usuários que apresentam sobreposição da vida pessoal e profissional e outros que procuram separar estas esferas. Os informantes adeptos a essa "mistura de mundos" são convictos ao darem suas respostas: "Eu recebo coisas 
pessoais e profissionais no mesmo e-mail. É um e-mail profissional e pessoal junto. A minha vida profissional é muito pessoal. Digo, não tem porque separar pessoal e profissional" (Informante 8).

Eu acho que ajo como qualquer outra pessoa que tá trabalhando e o celular toca... não vejo problema algum. Os e-mails eu só vejo à noite, os pessoais. Então, assim, eu acho que todo mundo hoje... todo mundo atende seu celular, né... Pouca gente não tem, é difícil viver sem. Então, todo mundo tem que trabalhar esses dois mundos (Informante 5).

Um deles relata que o fato de ter dois filhos morando fora do Brasil fez com que ele modificasse seu modo de trabalhar e se relacionar:

Um tá num fuso horário 5 horas à frente, e o outro 4 horas atrás. Então, a qualquer momento, eu estou trabalhando e vem uma mensagenzinha deles. Aí tu acabas atendendo, respondendo. Então, hoje eu estou conseguindo lidar com os dois ou três papéis até. Mas no início, não... eu colocava horários pra, por exemplo, só abrir/receber e-mails de trabalho (Informante 6).

Por outro lado, há aqueles que buscam separar a vida profissional da vida pessoal e que traçam algumas estratégias para isso, seja não abrindo a ferramenta de comunicação on-line como o MSN, não atendendo o celular, separando a caixa de e-mails ou desligando o celular da empresa nos finais de semana:

É prático ter todas as ferramentas aqui, e-mail, MSN, mas tem que saber... Tudo tem seu momento, né. Olha... quem tá me chamando aqui é a minha advogada, mas vou responder depois... O MSN, durante o dia eu uso o mínimo possível (Informante 7).

O Informante 2 pareceu bem-decidido com relação ao uso de tecnologias. Quando questionado se atendia o celular pessoal enquanto trabalhava, ele prontamente admitiu: "Dificilmente atendo o celular pessoal quando estou trabalhando. Mantenho o foco só no trabalho, se não eu me perco. Se eu começo a fazer outras coisas ao mesmo tempo eu não rendo" (Informante 2). Nessa fala, fica visível a dificuldade de trabalhar nos dois âmbitos ao mesmo tempo.

A estratégia de separar os e-mails foi relatada por dois trabalhadores móveis. A Informante 4, enquanto explicava como fazia, ia mostrando as suas diversas caixas de e-mails:

[...] nesse xxxxx@terra são os e-mails da minha Confraria, meu lazer. Agora, eu tenho diversos alternativos. Nesta caixa do Outlook... daí quando lido com o trabalho remunerado fico somente nele. Então, o fato de separar me ajuda a manter a concentração... Estou ali e desligo de tudo (Informante 4).

Os e-mails pessoais são separados, né. Caixas diferentes, endereços diferentes Tem o Outlook que eu uso, é só profissional. Então, claro que vem um monte de porcaria junto, né... e a gente acaba lendo pra ver o que é, mas eu consigo separar (Informante 6).

Desligar o celular nos finais de semana também é uma forma de evitar que o contexto pessoal seja afetado pelo profissional, como destaca o informante que estava trabalhando com seu notebook, enquanto sua esposa o aguardava:

[...] com certeza atrapalha a vida pessoal. Uma maneira, que eu achei pra desligar um pouco é ter um telefone da empresa e um pessoal. Os clientes não têm o meu pessoal. Então, tu chega às 7, 8 da noite, por aí às vezes. 0 da empresa eu deixo atirado, se a gente vai sair, vai no cinema, alguma coisa. Eu levo só o pessoal, só quem tem são os amigos, família [...] Porque tem clientes que é domingo, 10 horas da noite e tão te ligando 
pra resolver problema. Aí deixo no vibra ali e fica final de semana atirado... só vou pegar domingo de noite pra dar uma olhada e segunda de manhã. Foi a forma que achei. Ah, é final de semana tu tá... Não tinha como. Era o tempo todo cliente ligando (Informante 2).

\section{CONSIDERAÇÕES FINAIS}

As pessoas costumam ir ao shopping com a finalidade de fazer compras, de passear, de se divertir e de encontrar amigos, sendo o hábito de ir a esse espaço para trabalhar pouco habitual, como constatado neste estudo. Neste caso, a escolha do shopping como local para trabalho significa a otimização do chamado "tempo morto", como cunhado por Perry et al. (2001). Sabendo que possuem um tempo em que outras atividades não poderiam ser feitas, devido ao deslocamento e ao trânsito ou ao horário, os trabalhadores móveis tem no shopping um espaço de "parada estratégica", um local para poder otimizar uma parcela de tempo do seu dia a dia que estaria "morta".

Ao buscar compreender como os trabalhadores móveis lidam com as sobreposições de tempo, espaço e contexto, propiciadas pela mobilidade, alguns fatores merecem atenção. $O$ fato de os informantes estarem trabalhando de forma móvel, com dispositivos tecnológicos, não significa que a mobilidade espacial se configura como tranquila, posto que questões intrínsecas ao shopping, como barulho, conversas e cheiro de comida, são pequenos elementos que tendem a desviar a atenção, desconcentrando os indivíduos no exercício de suas atividades. Assim, muitos deles fazem uso de estratagemas, a exemplo da realização de tarefas mais operacionais quando se encontram no shopping ou até mesmo da utilização de abafadores de ouvido visando minimizar as influências do ambiente na concentração para o exercício das atividades profissionais.

A mobilidade de tempo é vista ora como difícil de ser administrada, pois alguns descrevem situações em que executam diversas atividades ao mesmo tempo, durante todos os dias da semana, ora como uma vantagem, tendo em vista a flexibilidade que as ferramentas de comunicação propiciam. Esse fato é exemplificado quando do recebimento de um e-mail, em que existe a possibilidade de respondê-lo na hora ou no momento em que o usuário julgar mais conveniente. Para Estrada, Flores e Schimith (2011, p. 317), "o foco na execução de atividades importantes e a redução do desperdício ou da má utilização do tempo representam demandas comuns das pessoas da era do conhecimento e da informação e exigem a reavaliação individual da forma como se ocupa o tempo".

O e-mail é bastante destacado quando se investiga a mobilidade contextual que as TIMS oportunizam, pois cria uma relação indiscreta (LJUNGBERG; SORENSEN, 2000), adentrando na vida do indivíduo, de forma um tanto invasiva, e leva, por vezes, a sobreposições entre a vida pessoal e profissional. Família e trabalho intercruzam-se na caixa de e-mail a qualquer momento. Alguns utilizam estratégias para separar estes dois mundos, outros afirmam ser normal e necessário saber lidar com estes dois contextos.

Na prática organizacional, é possível ver a mobilidade como impulsionadora da formação ad hoc de contatos e relacionamentos contextualizados. Como destacam Pica e Kakihara (2003, p. 8), "nossa realidade organizacional torna-se fluida e estável ao mesmo tempo, ela move-se conosco em diferentes contextos através do artefato móvel e influencia nossa percepção do espaço real". É justamente essa possibilidade de criação de inúmeros contextos móveis e diversas práticas de uso que merece ser pensada pelas organizações.

No âmbito acadêmico, entende-se que esta pesquisa pode contribuir com os estudos sobre experiências de uso de tecnologias móveis, a fim de ampliar o entendimento dos modos de trabalhar na contemporaneidade. "O uso de tecnologia não é uma escolha entre um conjunto fechado e pré-definido de possibilidades, mas um processo de constituição situado e recursivo" (ORLIKOWSKI, 2000, p. 209) que envolve aspectos sociais e materiais, os quais, naturalmente, são imbricados em suas práticas de uso. 
Cabe ressaltar, ainda, que o estudo foi realizado em um Shopping Center caracterizado como um "não lugar". Lugar é entendido por Augé (1993) como espaço de identidade, relacional e histórico. Para o autor, certos fenômenos do mundo contemporâneo caracterizam a sobremodernidade, a qual compreende três figuras de excesso: a superabundância de acontecimentos, a superabundância de espaços e a individualização das referências. Logo, um fenômeno característico da sobremodernidade é o não lugar, isto é, um espaço que não pode ser definido como espaço de identidade, relacional e histórico (AUGÉ, 1994), tornando-se um espaço de anonimato.

O espaço social do "cantinho" do Shopping não permite o estabelecimento de relações e vínculos, visto que, sendo um não lugar, cada indivíduo ali se estabelece e permanece focado em seu trabaIho e com as suas tecnologias, como se estivesse em uma cápsula, fechado e isolado dos demais. A interação que ele estabelece é com o "outro lado", ou seja, com aqueles que não estão ali presencialmente.

Diante disso, é possível afirmar que o não lugar é exatamente um reflexo dessa mobilidade que tende a isolar as pessoas no âmbito físico para colocá-las em contato através do meio virtual. Não lugar e Tecnologias de Informação e Comunicação Móveis e Sem Fio (TIMS) são característicos de um tempo de fluidez, de laços frágeis, de sociedades líquido-modernas, "em que as condições sobre as quais agem seus membros mudam num tempo mais curto do que aquele necessário para a consolidação, em hábitos e rotinas, das formas de agir" (BAUMAN, 2009, p. 7). Assim, torna-se complexo investigar esse tipo de fenômeno, tendo em vista a dificuldade de estabelecer uma relação mais próxima com os informantes.

Outra limitação deste estudo consiste no fato de que não foi possível acompanhar as mesmas pessoas durante o período de campo, visto que não havia rigor por parte dos trabalhadores móveis quanto à frequência de ida ao Shopping. Acredita-se que, se as inserções fossem repetidas mais vezes, seria possível encontrar as mesmas pessoas e, assim, identificar possíveis hábitos do trabalho móvel com mais acuidade.

Para estudos futuros, sugere-se replicar esta pesquisa em outros locais frequentados por trabalhadores móveis, como aeroportos, a fim de verificar outros comportamentos e estratégias de enfrentamento da sobreposição de local, tempo e contexto. Visando a um estudo mais aprofundado do tema, sugere-se, também, buscar na sociomaterialidade, proposta por Orlikowski (2007), a sustentação teórica para refletir sobre os aspectos materiais (tecnológicos) e sociais (humanos) do trabalho móvel, que na prática são indissociáveis, sendo somente separáveis analiticamente. Nesse sentido, a pesquisa organizacional poderia considerar os aspectos materiais e sociais da interação entre o trabalhador móvel, a tecnologia e o ambiente, constitutivamente emaranhados.

\section{REFERÊNCIAS}

ADMINISTRADORES.COM. Cresce o uso de dispositivos móveis no ambiente de trabalho. 2012. Disponível em: http:// www.administradores.com.br/informe-se/ tecnologia/cresceo-uso-de-dispositivosmoveis-no-ambiente-de-trabalho/65213/ Acesso em: 06 de Agosto de 2013.

ANDRIESSEN, E; VARTIAINEN, M. Emerging Mobile Virtual Work. In: ANDRIESSEN, E.
VARTIAINEN, M (Eds.) Mobile Virtual Work: A New Paradigm?Heidelberg: Springer, 2006.

AUGÉ, M. Não-Lugares: Introdução a uma antropologia da supermodernidade. Campinas: Papirus, 1994.

BARLEY, S. R. On Technology, Time, and Social Order: Technically Induced Change in the Temporal Organization of Radiological Work. In Making Time: Ethnographies of HighTechnology Organizations.F.A. Dubinskas ed. Philadelphia, PA: Temple University Press, 
1988.

BAUMAN, Z. Vida Líquida. Rio de Janeiro: Jorge Zahar, 2009.

CASTELLS, M. et al.The Mobile Communication Society: A cross - cultural analysis of available evidence on the social uses of wireless communication technology. International Workshop on Wireless Communication Policies and Prospects: A Global Perspective: 327 p., 2004.

CAVEDON, N. R.Antropologia para Administradores. Porto Alegre: UFRGS, 2003.

CHEN, L.; NATH, R. Nomadic Culture: cultural support for working anytime, anywhere. Information Systems Management, v. 22(4), 56-64, 2005.

COMPUTERWORLD. Com aumento do uso de smartphones e tablets, gestão de dispositivos vai decolar. 2012. Disponível em: http://computerworld.uol.com.br/ negocios/2012/10/26/com-aumento-douso-de-smartphonese-tablets-gestao-dedispositivos-vai-decolar/. Acesso em: 03 de Agosto de 2013.

ESTRADA, R. J. S.; FLORES, G. T.; SCHIMITH, C. D. Gestão do tempo como apoio ao planejamento estratégico pessoal. Rev. Adm. UFSM, Santa Maria, v. 4, n.1, p. 315-332 mai./ago. 2011.

GODOY, A. Pesquisa qualitativa: tipos fundamentais. Revista de Administração de Empresas, v. 35, n. 3, mai.-jun, p. 20-29, 1995.

IDG NOW. Estudo aponta smartphone como maior oportunidade para o e-commerce. Disponível em: http://idgnow.uol.com. br/mercado/2012/02/24/estudo-apontasmartphonecomo-maior-oportunidade-parao-e-commerce/. Acesso em: 03 de Agosto de 2013.

IT WEB. Especial smartphones: melhora da economia deve aumentar demanda. Disponível em: http://www.itweb.com.br/ noticias/index.asp?cod=69112. Acesso em: 03 de Julho de 2010.

KAKIHARA, M.; SORENSEN, C. Mobility: anextended perspective. In: Proceedings of the Hawaii International Conference on System Sciences, 35, Big Island, Hawaii, IEEE, 2002.

KLEINROCK, L. Breaking loose. Communications of the ACM, vol.44 (9), pp. 41-45. 2001.

KORNAK, A. Wireless and Mobility Defined. In: KORNAK, A.; TEUTLOFF, J.; WELIN-BERGER, M. Enterprise Guide to Gaining Business Value from Mobile Technologies. Hoboken, NJ: Wiley Publishing, Inc, 2004.

LOUREIRO A. A. F. et al. Comunicação Sem Fio e Computação Móvel: Tecnologias, Desafios e Oportunidades. In: Mini Curso. Congresso da Sociedade Brasileira de Computação, Campinas/SP, 2004.

LJUNGBERG, F; SORENSEN, C. Overload: From Transaction to Interaction. In Planet Internet. K. Braa, C. Sorensen, and B. Dahlbom eds., Lund, Sweden: Studentlitteratur, pp. 113-136, 2000.

MALINOWSKI, B. Argonautas do Pacífico Ocidental. São Paulo: Abril Cultural, 1978.

MYERS, A. et al. Taking Handeld Devices to the Next Level. IEEE Computer Society, December, p. 36-43, 2004.

ORLIKOWSKI, W.; YATES, J. It's about time: Temporal structuring in organizations, Organization Science, nov/ dec, pp. 685-695, 2002.

ORLIKOWSKI, W. J. Sociomaterial Practices: Exploring Technology at Work. Organization Studies, 28:9, p. 1435-1448, 2007.

PERRY, M.et al. Dealing with Mobility: Understanding Access Anytime, Anywhere.

ACM Transactions on Computer-Human Interaction, v.8, n.4, p.323-347, 2001. 
SACCOL, A.; REINHARD, N. Tecnologias de Informação Móveis, Sem Fio e Ubíquas: Definiçőes, Estado-da-Arte e Oportunidades de Pesquisa, Revista de Administração Contemporânea, 2007.

SILVEIRA, R. B.; SINEM, M. Quem te viu, quem te vê: as mudanças do composto mercadológico do varejo de shopping centers da região do vale do Itajaí/SC durante a sua existência, Rev. Adm. UFSM, Santa Maria, v. 2, n. 2, p. 214-234, maio/ago. 2009.

VANCE, P. de S.; ANGELO, C. F. de; FOUTO, N. M. M. D. Estudo do Comportamento de Compra do Frequentador de Shopping Centers na Cidade de São Paulo. Rev. Adm. UFSM, Santa Maria, v. 2, n. 1, p.130-146, jan./abr. 2009.

VELHO, G. Individualismo e Cultura: notas para uma antropologia da sociedade contemporânea. Rio de Janeiro: Jorge Zahar, 1981. 